\title{
Ação comunicativa e ética no acesso e uso sustentável da água: a experiência do saneamento rural de Marechal Cândido Rondon - Paraná
}

\author{
Communicative action and ethics on the access and sustainable use of water: \\ the experience of rural sanitation of Marechal Cândido Rondon - Paraná, Brazil
}

\begin{abstract}
Alvori Ahlert *
Resumo

O texto apresenta um estudo/pesquisa sobre a ética e os recursos hídricos, problematizando a relação entre a ética e o uso sustentável da água, tendo como modelo referencial aproximações na experiência do saneamento rural de Marechal Cândido Rondon, PR que, através da organização dos próprios agricultores e com o apoio da autarquia municipal de água e esgoto, atingiu $100 \%$ de acesso à água potável na zona rural do município. A discussão propõe uma sinergia entre comunidades, gestores de sistemas e pesquisadores, que possibilite a criação de contextos comunicativos nos quais se partilha e socializa informações para o debate dos temas e situações que defendam um acesso democrático aos recursos hídricos e ao uso sustentável da água. Os fundamentos para este debate se encontram na obra de Lord Selborne, A Ética do Uso da Água Doce: um levantamento. (2001), e no paradigma da Teoria da Ação Comunicativa de Jürguen Habermas (1989), como um instrumento para propor o debate público sobre o acesso democrático aos recursos hídricos e, assim, criar contextos comunicativos que possibilitem a socialização de conhecimentos necessários relativos aos recursos hídricos e potencializar o debate sobre o uso desse bem natural como um direito humano universal.
\end{abstract}

Palavras-chave: Ética. Água. Uso sustentável. Ação comunicativa. Saneamento rural.

\begin{abstract}
The text presents a study/research on ethics and water resources, questioning the relationship between ethics and sustainable water use, taking as reference model approaches in the experience of rural sanitation of Marechal Cândido Rondon, PR that, through the organization's own farmers, with the support of a municipal water and sewer, reached $100 \%$ access to safe drinking water in the rural area. The discussion proposes a synergy between communities, systems managers and researchers, enabling the creation of communicative contexts in which information is shared and socialized for discussion of issues and situations that advocate democratic access to water resources and the sustainable use of water. The grounds for this debate are the work of Lord Selborne, The Ethics of Freshwater Use: A survey. (2001), and the paradigm of the Theory of Communicative Action by Jürguen Habermas (1989), as an instrument to propose a public debate on democratic access to water resources and thus create communicative contexts that enable socialization of required knowledge of the water resources and enhance the debate on the use of this natural asset as a universal human right.
\end{abstract}

Keywords: Ethics. Water. Sustainable use. Communicative action. Rural sanitation.

\footnotetext{
Artigo recebido em 13 de agosto de 2013 e aprovado em 07 de outubro de 2013.

* Doutor em Teologia. Professor Adjunto da Universidade Estadual do Oeste do Paraná (UNIOESTE). País de origem: Brasil. E-mail: alvoriahlert@yahoo.com.br.
} 


\section{Introdução}

A água é condição indispensável para a existência da vida. Como recurso natural insubstituível na maioria das ações humanas, ela está presente não somente como necessidade básica (saciar a sede, higienização e saneamento básico), mas também como um mecanismo de desenvolvimento em seus componentes econômicos e sociais através do abastecimento em massa para as populações, para as indústrias, para a irrigação da produção de alimentos, para a manutenção dos ecossistemas, para a produção de energia. Além disso, cada vez mais se configura como condição para o turismo e o lazer. Por isso, ela significa um bem natural de disputas radicais entre políticas públicas e interesses privados no século XXI. Consequentemente, sua proteção, justa distribuição, tratamento e uso sustentável demandam a construção do seu ethos ${ }^{1}$ privilegiado nas comunidades urbanas e rurais em todo o planeta. O uso sustentável da água requer princípios éticos de defesa radical da vida de todos e de tudo, do qual a vida plena e de qualidade dependem para a sua existência.

Assim, a presente pesquisa tem por objetivo problematizar a relação entre a ética e o uso sustentável da água e defender essa relação necessária com base em processos de ação comunicativa que envolva as comunidades, os gestores dos sistemas de produção, abastecimento e tratamento e as sociedades científicas que desenvolvem conhecimentos para um uso sustentável desse bem natural para a vida da humanidade.

Uma ética que produza cuidados para com o uso sustentável se interioriza mediante conhecimentos compartilhados entre todos os concernidos sobre o tema. Não se cuida o que não se conhece. Não se preserva se não se conhecem os sentidos

\footnotetext{
${ }^{1}$ Para o teólogo e escritor Frei Leonardo Boff, ethos pode ser definido como um "[...] conjunto das inspirações, dos valores e dos princípios que orientarão as relações humanas para com a natureza, para com a sociedade, para com as alteridades, para consigo e para com o sentido transcendente da existência: Deus." (BOFF, 2000, p. 20). Para o antropólogo Glifford Geertz, a definição de ethos se evidencia como visão de mundo de um povo com a qualidade de vida, com a moralidade e a estética. "O ethos de um povo é o tom, o caráter e a qualidade de sua vida, seu estilo moral e estético, e sua disposição é a atitude subjacente em relação a ele mesmo e ao seu mundo que a vida reflete. A visão de mundo que esse povo tem é o quadro que elabora das coisas como elas são na simples realidade, seu conceito da natureza, de si mesmo, da sociedade". (GEERTZ, 2008, p. 93) Por isso, para o contexto de nossa pesquisa um ethos para a água significa a responsabilidade de uma comunidade com sua morada, seu abrigo como perspectiva externa, e, como perspectiva interna, o cuidado, o caráter os hábitos no tocante a água com bem preciso fundamental para a vida de todos.
} 
da preservação. Por isso, uma sinergia entre comunidades, gestores de sistemas e pesquisadores, possibilita a criação de contextos comunicativos nos quais se partilha e socializa informações para o debate dos temas e situações que garantam um uso sustentável da água.

$\mathrm{O}$ estudo/pesquisa divide-se em duas partes. Na primeira problematiza-se a relação entre a ética e o uso sustentável da água. Para a reflexão conexa entre ética e uso sustentável da água, apoiaremos nossa pesquisa na obra de Lord Selborne, $A$ Ética do Uso da Água Doce: um levantamento, publicada em 2001. Na segunda parte do texto apresentamos a Teoria da Ação Comunicativa de Jürguen Habermas (1989) como um instrumento de trabalho para iniciativas relacionadas a um debate público e a formação permanente de todos os envolvidos com a questão água, bem como à socialização de conhecimentos necessários relativos à água, capazes de potencializar o debate sobre o uso desse bem natural como um direito humano universal.

O presente artigo tem como objetivo investigar, através de uma pesquisa exploratória e bibliográfica que, segundo Gil (1999, p. 65), “é desenvolvida a partir de material já elaborado, constituído principalmente de livros e artigos científicos”, associado a um estudo de caso (o saneamento rural do município de Marechal Cândido Rondon - PR), que, segundo Alvim Antônio de Oliveira Netto (2006, p. 14) possibilita "[...] explicar ou descrever um sistema de produção ou sistema técnico no âmbito particular ou coletivo [...]”, a relação entre a ética e o uso sustentável da água e a construção de um ethos onde este tema se torne debate público com conhecimento de causa de todos os envolvidos com este símbolo comum da vida no planeta. Esse tipo de pesquisa nos permite construir novos conhecimentos e disseminar princípios éticos relacionados à água a partir das contribuições científicas já realizadas sobre o tema. 


\section{Resultados e discussão}

Para falarmos sobre a ética em sua relação com o uso sustentável da água², faz-se necessário partirmos de um conceito mínimo de ética. "Ética é um conjunto de princípios e valores que guiam e orientam as relações humanas. Esses princípios devem ter características universais, precisam ser válidos para todas as pessoas e para sempre." (SOUZA, 1994, p. 13). Portanto, a ética está ligada aos princípios como dignidade, participação, cooperação, solidariedade, igualdade, bem comum, economia, prudência, que orientam, normatizam, motivam e disciplinam o comportamento dos seres humanos face ao manejo e uso da água, que é um direito humano fundamental.

A consciência sobre a escassez de água tomou forma na segunda metade do século XX, e hoje é uma das principais preocupações da humanidade. Diversos países já se debatem com a falta de água. Por isso, o uso sustentável da água tornase um dos maiores desafios para os seis bilhões de habitantes humanos do Planeta Terra. O consumo maior de água ocorre na produção agrícola. Estima-se que a agricultura intensiva consome mais de quinhentos litros por pessoa ao dia. Para citar um exemplo, somente no oeste da Bahia está em curso um processo de irrigação do plantio de soja. "De acordo com a Associação de Agricultores e Irrigantes da Bahia, no oeste do Estado existem 982 pivôs instalados em lavouras de café e de soja.” (PIVOS, 2013). Vale lembrar que uma área de 125 ha de café irrigada com dois sistemas de pivô central consome $260 \mathrm{~m}^{3} / \mathrm{h}$ durante 14,5 horas. (REIS et alii). Ainda no caso da agricultura, Dal Marcondes (2013), em seu artigo Fluidez para os negócios, reproduz dados da Water Footprint.org que mostram a quantidade de água que é consumida para a produção:

\footnotetext{
${ }^{2}$ Entendo o uso sustentável da água no contexto do desenvolvimento sustentável. Conforme Mark Mawhinney, já existe um grande número de descrições, explicações e definições para desenvolvimento sustentável. Para o contexto de nossa discussão optamos pela primeira definição apresentada pelo autor, isto é, a de Brundtland, publicada em 1987, que definem o desenvolvimento sustentável como aquele "[...] que provê as necessidades do presente sem comprometer a capacidade das futuras gerações de prover suas próprias necessidades." (MAWHINNEY, 2005, p. 11). Acredito que esta definição se enquadra muito bem na perspectiva do uso sustentável da água.
} 
Quadro 1: Consumo de água no agronegócio

\begin{tabular}{|c|c|}
\hline PRODUTO & Consumo de água \\
\hline 1 litro de cerveja & 5,5 litros de água \\
\hline $1 \mathrm{~kg}$ de arroz & 2,5 mil litros de água \\
\hline $1 \mathrm{~kg}$ de manteiga & 18 mil litros de água \\
\hline 1 litro de leite & 712,6 litros de água \\
\hline $1 \mathrm{~kg}$ de queijo & 5,3 mil litros de água \\
\hline $1 \mathrm{~kg}$ de batata & 132,5 litros de água \\
\hline $1 \mathrm{~kg}$ de carne bovina & 17,8 mil litros de água \\
\hline $1 \mathrm{~kg}$ de banana & 499 litros de água \\
\hline $1 \mathrm{~kg}$ de frango & 3,5 mil litros de água \\
\hline $1 \mathrm{~kg}$ de soja & 2,5 mil litros de água \\
\hline
\end{tabular}

Fonte: MARCONDES. 2013, p. 36.

Em segundo lugar, vem o uso da água pelas indústrias e em terceiro lugar o uso doméstico da água. No caso da indústria, Dal Marcondes, no já referido texto, lembra que também a indústria é uma grande consumidora de água. “[...] a fabricação de automóveis. Cada unidade necessita, em média, de 60 mil litros de água. Em 2012 foram produzidos 3,34 milhões de automóveis em todas as montadoras que operam no país. Isso representa a necessidade de 2 trilhões de litros d'água para abastecer as montadoras e fábricas de autopeças nesse período". (MARCONDES, 2013, p. 37) O referido autor ainda reproduz dados da Water Footprint.org a cerca da quantidade de água gasta em indústrias cujos produtos usamos diariamente:

Quadro 2: Consumo de água na indústria

\begin{tabular}{|c|c|}
\hline PRODUTO & Consumo de água \\
\hline 1 automóvel & 55 mil a 83 mil litros de água \\
\hline 1 computador & 1,5 mil litros de água \\
\hline 1 kg de couro & 16,6 mil litros de água \\
\hline 1 calça jeans & 15 mil litros de água \\
\hline 1 camiseta de algodão & 3,7 mil litros de água \\
\hline 1 kg de papel & 324 litros de água \\
\hline 1 kg de aço & 95 litros de água \\
\hline 1 litro de gasolina & 10 litros de água \\
\hline
\end{tabular}

Fonte: MARCONDES, 2013, p. 36. 
Mas, conforme Selborne (2001, p. 25), "Segundo o Conselho de Suprimento de Água e Serviços Sanitários, cerca de 1,4 bilhão de pessoas (25\% da população mundial) ainda não têm acesso ao fornecimento regular de água, e 2,9 bilhões (5060\% da população mundial) têm falta de serviços sanitários básicos.” Essa realidade demanda princípios éticos para o uso da água. $\mathrm{E}$ isso tem levado os debates sobre a administração dos recursos hídricos para um confronto com a ética social. A Declaração Universal dos Direitos Humanos, das Nações Unidas, de 1948, e a proclamação da Conferência das Nações Unidas sobre a Água, de 1977. Nela os signatários assumiram que "todos os povos... têm direito ao livre acesso à água potável em quantidades e de qualidade iguais às das suas necessidades básicas". Isso significa que o uso da água necessita de princípios éticos norteadores, assim resumidos por Selborne:

O princípio da dignidade humana, pois não há vida sem água, e àqueles a quem se nega a água nega-se a vida; o princípio da participação, pois todos os indivíduos, especialmente os pobres, precisam estar envolvidos no planejamento e na administração da água, e na promoção desse processo se reconhece o papel do gênero e da pobreza; o princípio da solidariedade, pois a água confronta os seres humanos com a interdependência, a montante e a jusante, e as propostas correntes de uma administração integrada dos recursos hidráulicos podem ser vistas como uma conseqüência direta dessa consciência; o princípio da igualdade humana, entendido como a concessão a todas as pessoas do que lhes é devido, e que descreve perfeitamente os desafios atuais da administração das bacias fluviais; o princípio do bem comum, pois, segundo a definição aceita por quase todos, a água é um bem comum, e se não for administrada adequadamente a dignidade e o potencial humanos ficam reduzidos para todos, e são negados a alguns; o princípio da economia, que ensina o respeito pela criação e o uso prudente, e não uma reverência extremada pela natureza; com efeito, boa parte da administração hídrica diz respeito ao encontro de um equilíbrio ético entre o uso, a mudança e a preservação da nossa terra e dos recursos hidráulicos. (SELBORNE, 2001, p. 26-27)

Estes princípios devem ser incorporados aos sistemas que manejam a água doce em nosso planeta. Entretanto, eles não se corporificam se estes sistemas não fomentarem uma intensa participação de todos os concernidos. O princípio da participação torna-se um pilar estruturante para os demais princípios. Por isso uma pergunta se coloca na mesa dos debates: Que paradigma pode garantir esta participação de todos os concernidos? 
Entendo que o paradigma habermasiano sobre a Teoria da Ação Comunicativa e da Ética do Discurso, como apresentados na obra, Consciência moral e agir comunicativo (1989), pode referenciar a ação ética para os sujeitos implicados com a questão da água no século XXI. Em sua crítica à Modernidade, Habermas afirma que a crise da modernidade foi conseqüência do "desengate" entre o mundo da vida e o sistema, pois a dissociação fez com que os seres humanos fossem submetidos às leis do mercado capitalista e à burocracia do Estado. A razão comunicativa foi eliminada do processo, suprimindo a reserva de valores que permitiriam o questionamento e a discussão de princípios fundamentais como a verdade, a moralidade e a expressividade necessárias para a concepção de fins segundo o interesse da maioria.

No contexto da crise da Modernidade, o mercado capitalista e a burocracia se constituíram como forças gigantescas, criando a sensação de dependência total e exaurindo qualquer força de resistência por parte da sociedade. A sociedade tornou-se apática, o que permitiu à minoria rica e seus burocratas ditarem as regras do jogo societário sobre a maioria. A racionalização, razão instrumentalizada, invadiu o mundo da vida. Foi uma nova forma de colonização. O sistema passou a impor seu jogo dominador através da economia e da política. (FREITAG, 1993) A razão comunicativa foi eliminada do processo, suprimindo a reserva de valores que permitiriam o questionamento e a discussão de princípios fundamentais como a verdade, a moralidade e a expressividade necessárias para a concepção de fins segundo o interesse da maioria. "A crítica centra-se no modelo de dominação da sociedade avançada que submete a individualidade à totalidade social, restringindo o agir a tal ponto que não resta outra saída senão aderir a essa sociedade.” (PIZZI, 1994, p. 27)

Com isso, os grandes temas pertinentes às pessoas no mundo da vida deixaram de ser debatidos e analisados criticamente. Não há dúvidas de que essa modernidade, que retirou a racionalidade do mundo da vida, é hoje umas das grandes ameaças para o acesso universal aos recursos hídricos. O paradigma da 
modernidade tirou das comunidades a capacidade de se indignar, de se organizar coletivamente diante das injustiças; destruiu a capacidade argumentativa diante dos problemas que atingem a coletividade, impedindo uma reação organizada para a defesa dos interesses da comunidade. No caso da água, um belíssimo Conto, intitulado A assembléia frustrada 3 de Silvio Meincke, narra a incapacidade de uma comunidade enfrentar a privatização da água, o que coloca o futuro dessa comunidade numa "insegurança hídrica”.

Diante dessa realidade podemos encontrar na Teoria da Ação Comunicativa formas organizativas de comunidades em defesa do acesso e uso sustentável da água. Habermas propõe um novo paradigma, no qual a racionalidade comunicativa se efetiva por meio de uma ação comunicativa elaborando estruturas capazes de dar um sentido comum aos sujeitos comunicativos através do inter-relacionamento entre o mundo da vida e a sociedade.

Por "ação comunicativa" entende Habermas a ação social na qual os planos de ação dos diferentes agentes se encontram coordenados por meio de "ações de fala", na qual os falantes pretendem "intelegibilidade" para o que dizem, "verdade" para o conteúdo do que dizem ou para as pressuposições de existência do que dizem quando da 'ação de fala' de coerção; "retidão" para as suas ações de fala no relação com o contexto normativo vigente, para esse contexto normativo, e "veracidade" para seus atos de fala como expressão do que pensam.(REDONDO, 1991, p. 9-10)

Esses pressupostos fundamentam outro elemento na estrutura da teoria de Habermas: a Ética do Discurso. A Ética do Discurso levanta a discussão sobre "o que fazer". (HABERMAS, 1989) Com a Ética do Discurso, concretizada num contexto comunicativo, caracterizado pela argumentação, que envolva as comunidades, os gestores e os especialistas envolvidos com o manejo, consumo, e proteção da água a partir de uma fundamentação em Habermas, possibilita um salto qualitativo para além da ética individualista kantiana. No imperativo categórico de Kant é o sujeito perguntando sobre “O que devo fazer?” Na ética

\footnotetext{
${ }^{3} \mathrm{O}$ autor narra uma historia na qual todos os animais de uma certa região muito seca consumiam a água de um lago. Entretanto, o animal mais forte, o leão, criara um desvio de água para a sua propriedade, o que fez com que o nível do lago baixasse a olhos vistos. Diante disso, o pato sugeriu uma assembléia para definir uma sindicância. Mas todos os outros animais, um a um, foram se esquivando, ou por medo, ou por dependência do poder do leão e abandonaram a assembléia, frustrando a iniciativa de buscar uma solução para a insegurança hídrica que se avizinhava. Assim, praticamente sozinho, o pato, desanimado, também desistiu. (MEINCKE, 1983, p. 34-36).
} 
discursiva comunitária esta pergunta sobre “O que fazer?", torna-se um processo de sujeitos solidários plurais fazendo emergir perguntas sobre "O que devemos fazer?", e "Que valores e normas seguir?", concernentes aos compromissos com a questão do manejo e consumo da água no mundo da vida. (AHLERT, 2003). O consenso passa a ser construído pela vontade comum. Isso pressupõe um processo cooperativo, um processo que reinventa a comunidade em torno de seu bem mais precioso para a vida: a água.

A construção de contextos comunicativos, nos quais se exerce a ética da participação, possibilita transpor as barreiras do egoísmo e abrir caminhos para construções coletivas. Grupos humanos, diante de suas necessidades, buscam parcerias e trocam informações. Assim, criam espaços institucionais que se transformam em contextos comunicativos nos quais se buscam soluções consensuadas para as necessidades.

Quadro 3 - Construção de um contexto comunicativo

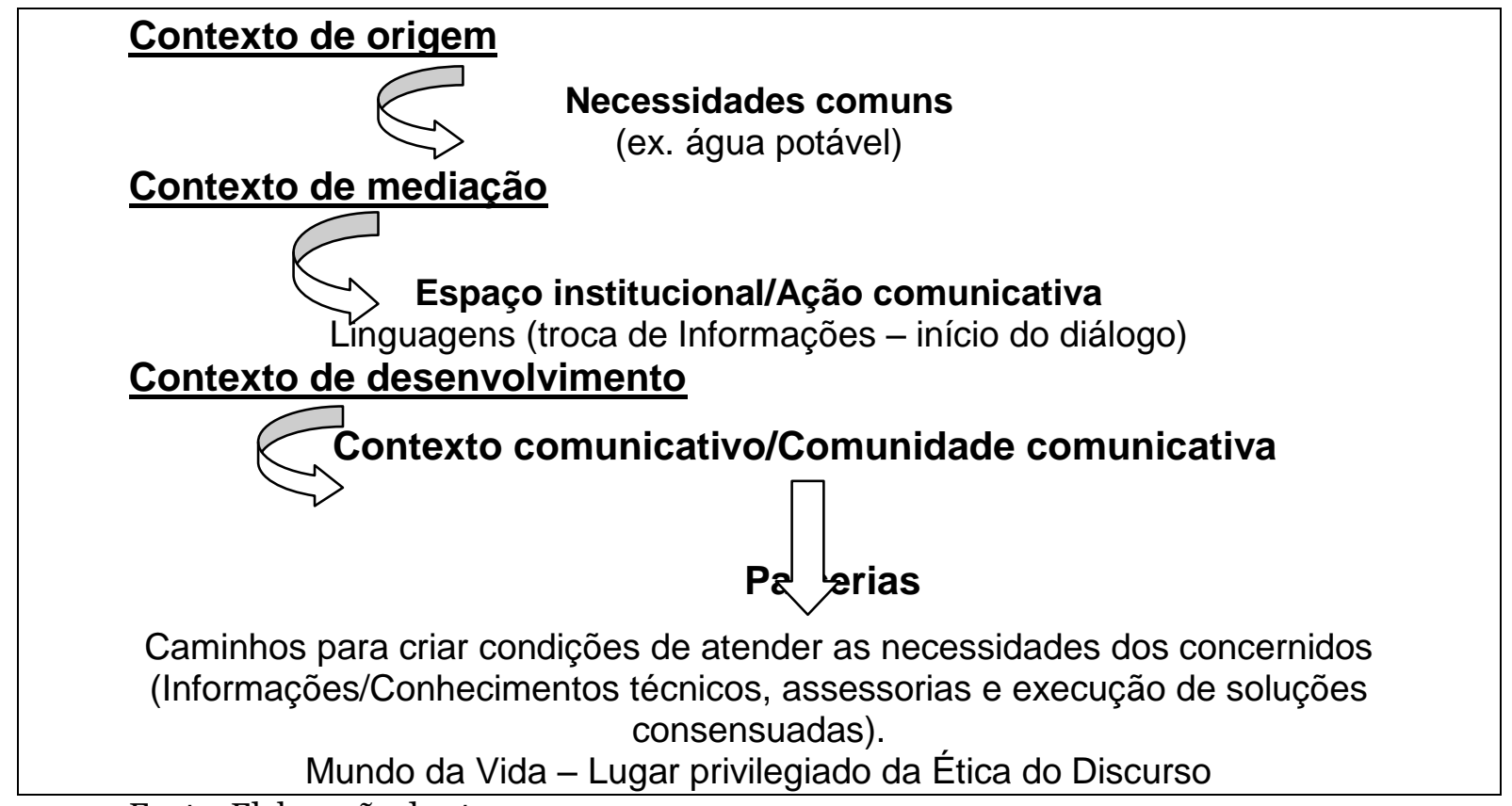

Fonte: Elaboração do atuor. 
Tendo a questão da água como uma necessidade, as pessoas do mundo da vida local criam contextos comunicativos nos quais se realizam processos de linguagens que levam ao diálogo e, assim, surgem movimentos em favor da busca por soluções para seus problemas. Habermas aponta para procedimentos argumentativos no grupo para a construção de consensos. Neste processo indivíduos, isolados anteriormente, descobrem que o bem-estar depende da coletividade. Dá-se uma ação conjunta em favor da solução de problemas a partir da ação comunicativa.

\section{Um modelo de acesso e distribuição comunitária de água}

O município de Marechal Cândido Rondon, no oeste do Paraná, possui uma área territorial de $747.11 \mathrm{Km}^{2}$. Na sua origem o município era maior em área, mas houve várias emancipações de distritos que formaram novos municípios. "O município de Marechal Cândido Rondon foi instalado a 02 de dezembro de 1961, com uma área de $1.047 \mathrm{Km}^{2}$. A denominação de General Rondon foi uma homenagem a Marechal Cândido Mariano da Silva Rondon, que esteve na região em inspeção de fronteira, e na instalação de linhas telegráficas.” (FERRARI, 2009, p.59).

Marechal Cândido Rondon, com uma população de 46.819 habitantes (IBGE, 2013), está situado numa altitude de 420 metros acima do nível do mar,

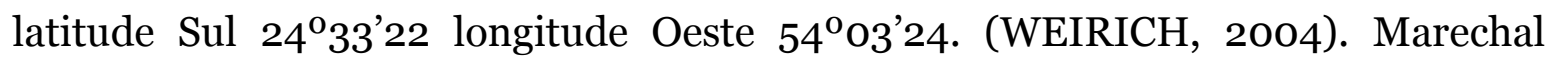
Candido Rondon limita-se ao Norte com o Município de Mercedes; ao Sul com o Município de São José das Palmeiras e Entre Rios do Oeste; a Nordeste com o Município de Nova Santa Rosa; a Leste com o Município de Quatro Pontes; a Sudeste com o Município de Toledo e Ouro Verde; a Sudoeste com o Município de Pato Bragado e ao Oeste com a República do Paraguai.

O saneamento básico do município é garantido pelo sistema de abastecimento de água de Marechal Cândido Rondon, uma autarquia municipal operada e mantida pelo Serviço Autônomo de Água e Esgoto (SAAE), criado em 
1966. O abastecimento de água é constituído por diversas captações de nascentes drenadas do lençol sub-superficial e também de poços tubulares profundos no aqüífero Serra Geral, distribuídos no perímetro urbano e na região periférica da cidade. O relatório de leitura da realidade municipal de 2007 atesta que mais da área rural era abastecida com água potável. “[...] a SAAE mais de 96\% da população residente na área rural do município é atendida pelo serviço público de abastecimento de água. De acordo com os dados demonstrados na tabela abaixo nota-se que a rede foi consideravelmente ampliada nos últimos anos (a partir de 2000), restando a implantação de apenas duas linhas, as quais juntas somam 37.280 metros de extensão, para que toda a área rural seja contemplada com este serviço.” (PREFEITURA MUNICIPAL DE MARECHAL CÂNDIDO RONDON, 2007, p. 246)

Mas conforme o Contador e ex-diretor Executivo Darci Ervino Schitz do SAAE, hoje $100 \%$ da população residente na área rural do município tem abastecimento de água realizada pelas Associações de Usuários “Águas Rurais”. Conforme Darci, o processo de implantação das associações iniciou em 1992 na gestão do Prefeito Dieter Leonhard Seyboth, pelo então Diretor Executivo, Haari Strenske. Diante da necessidade de água potável, pessoas residentes na área rural começaram a procurar auxílio junto ao SAAE. A partir desta procura, a Autarquia orientou essas pessoas para que constituíssem associações com a finalidade de organizar a construção dos seus sistemas de água.

Segundo Roseli Weber, Secretária Executiva da Autarquia, a partir da primeira experiência bem sucedida, foi-se criando um conhecimento que permitiu elaborar todos os passos a serem seguidos para que uma comunidade rural possa constituir seu próprio sistema de abastecimento de água. Todo o processo é organizado pelos próprios moradores de uma Linha Rural a partir da criação de sua associação. A partir disso recebem informações e orientação técnicas do SAAE, que também faz toda a execução da obra. A gestão deste sistema é realizada pela 
própria associação. Conforme o Contador e ex-diretor Executivo Darci Ervino Schitz do SAAE, a manutenção da rede física é realizada por moradores da própria Linha Rural, que foram treinados pelo SAAE para realizar tais serviços que são custeados pela própria associação, pois cada usuário da rede de água possui um hidrômetro e paga pelo custo da água recebida, o que tornou o programa muito eficiente, pois tais serviços pequenos tornam-se muito menos onerosos, sendo que o deslocamento de uma equipe do SAAE desde a sede traria despesas financeiras bem mais significativas.

A Figura 2 a seguir mostra em detalhes todo o roteiro desenvolvido pela equipe do SAAE para orientar uma comunidade rural para constituir sua associação e implantar seu sistema de acesso e distribuição de água.

Quadro 4 - Processo de implantação de sistema rural de abastecimento de água

\section{PROCESSO DE IMPLANTAÇÃO DE SISTEMA RURAL \\ DE ABASTECIMENTO DE ÁGUA}

a) Reunião com interessados em receber água tratada;

b) Levantamento a campo/ locação para perfuração de poço semi-artesiano;

c) Contratação de empresa para perfuração do poço;

d) Perfuração do poço/ teste de vazão;

e) Levantamento com GPS para efetuar projeto de distribuição de água;

f) Efetuado projeto social, com todas as famílias da localidade (Ex. Linha São Bernardo). Trabalho em campo;

g) Efetuar projeto com Engenheiro Civil;

h) Efetuado croqui de localização para averbação da área do poço e reservatório em escritura (proprietários que cedem a área tem isenção mensal de $30 \mathrm{~m}^{3}$ )

i) Solicitação de Outorga para uso da água;

j) Solicitação de padrão de energia elétrica;

k) Reunião com moradores para efetuar parceria (na maioria 50 osc milho por ligação). Este custo aproxima-se de $30 \%$ do valor total da obra. Apresentação do projeto aos moradores;

l) Assinatura dos contratos com usuários;

m) Reunião, para discussão e apresentação de um modelo de estatuto/ regimento interno. Principais normas são estabelecidas pelos moradores (taxa mínima e outros) Sempre com auxilio e indicação de técnicos da Autarquia;

n) Acompanhamento no registro e formação de diretoria da associação;

o) Contratação através de licitação e/ou outro, para abertura e fechamento de valas, bem como compra de material (Reservatório, tubulação, conexões, hidrômetros, etc.)

p) Contratação de mão de obra para construção da Casa de Tratamento;

q) Construção da casa de tratamento;

r) Instalação da rede de distribuição, feita por técnicos da Autarquia;

s) Instalação de barrilete e quadro de comando (parte elétrica), bem como dosador de cloro;

t) Teste na rede de abastecimento, instalação de hidrômetros;

u) Curso básico de como efetuar cloração, com 5 pessoas da comunidade, no local (casa de tratamento)

v) Solicitado ao operador do sistema, acompanhar funcionários da autarquia, para aprender na pratica como efetuar conserto de rede e ligações de água.

w) Levantamento in loco para locação de tubulação instalada, colocada em projeto. 
x) Inauguração oficial do sistema de tratamento de água;

y) Entrega de cópia de projeto/caderno de leitura/aviso de corte e outros documentos necessários.

z) Acompanhamento por 90 dias, do funcionamento do sistema de distribuição. Manutenções efetuadas pela Autarquia nesse período.

aa) Entrega do sistema a comunidade (após os 90 dias).

bb) Disponibilidade para auxílios futuros, caso necessário.

Fonte: Roseli Weber, Secretária Executiva do SAAE - Marechal Cândido Rondon, PR.

O município de Marechal Cândido Rondon alcançou 100\% de abastecimento de água para a população rural através do sistema de Associações de Usuários “Águas Rurais". O sistema garante o fornecimento de água potável através de 1.923 ligações, para 1.871 famílias que somam 6.806 pessoas, moradoras de 42 Linhas Rurais. São 713.387 metros de rede de abastecimento na área rural do município. A contribuição importante desta experiência é que ela aponta para um saneamento básico sob o controle da população, conforme aponta a Lei do Saneamento Básico no seu Cap. 3, Inciso IV “- controle social: conjunto de mecanismos e procedimentos que garantem à sociedade informações, representações técnicas e participações nos processos de formulação de políticas, de planejamento e de avaliação relacionados aos serviços públicos de saneamento básico".4

Quadro 5 - Saneamento rural de Marechal Cândido Rondon - PR

\begin{tabular}{|c|c|c|c|c|c|c|}
\hline \multicolumn{7}{|c|}{ SANEAMENTO RURAL NO MUNICÍPIO DE MAL. CÂNDIDO RONDON - PR } \\
\hline \multicolumn{7}{|c|}{ TOTAL DE TODOS OS SISTEMAS } \\
\hline \multirow{2}{*}{ No } & LINHA RURAL & No DE & No DE & No DE & EXTENSÃO DA \\
\cline { 5 - 8 } & FAMÍLIAS & LIGAÇÕES & PESSOAS & ANO DE \\
\hline 1 & L. AJURICABA & 64 & 63 & 224 & 30.534 & 1999 \\
\hline 2 & L. ARARA & 69 & 69 & 233 & 23.352 & 2004 \\
\hline 3 & L. APEPU / STA. MARIA & 51 & 48 & 175 & 20.873 & 2004 \\
\hline 4 & L. BANDEIRANTES & 81 & 81 & 281 & 21.754 & 1993 \\
\hline 5 & L. BELMONTE I e II & 85 & 84 & 307 & 38.768 & $2002 / 2004$ \\
\hline 6 & $\begin{array}{c}\text { L. BOA VISTA / ESQUINA } \\
\text { GUAIRA }\end{array}$ & 75 & 85 & 266 & 39.446 & 2006 \\
\hline
\end{tabular}

\footnotetext{
${ }^{4}$ LEI № 11.445, DE 5 DE JANEIRO DE 2007. Estabelece diretrizes nacionais para o saneamento básico; altera as Leis $\mathrm{n}^{\text {ㅇ }} 6.766$, de 19 de dezembro de 1979, 8.036, de 11 de maio de 1990, 8.666, de 21 de junho de 1993, 8.987, de 13 de fevereiro de 1995; revoga a Lei nำ6.528, de 11 de maio de 1978; e dá outras providências.
} 


\begin{tabular}{|c|c|c|c|c|c|c|}
\hline № & LINHA RURAL & $\begin{array}{l}\text { № DE } \\
\text { FAMÍLIAS }\end{array}$ & $\begin{array}{c}\text { № DE } \\
\text { LIGAÇÕES }\end{array}$ & $\begin{array}{c}\text { № DE } \\
\text { PESSOAS }\end{array}$ & $\begin{array}{l}\text { EXTENSÃO DA } \\
\text { REDE }\left(\mathrm{m}^{2}\right)\end{array}$ & $\begin{array}{c}\text { ANO DE } \\
\text { CONCLUSÃO }\end{array}$ \\
\hline 7 & L. CAMPO SALES & 35 & 37 & 125 & 20.232 & 2006 \\
\hline 8 & L. CINCO CANTOS & 9 & 8 & 31 & 3.765 & 2003 \\
\hline 9 & L. CONCORDIA & 35 & 30 & 97 & 8.696 & 1999 \\
\hline 10 & $\begin{array}{l}\text { L. CURVADO / TERRA } \\
\text { BRANCA }\end{array}$ & 44 & 44 & 137 & 21.568 & 2002 \\
\hline 11 & L. ESQUINA HORIZONTE & 13 & 13 & 52 & 6.150 & 1987 \\
\hline 12 & L. GAÚCHA & 48 & 53 & 189 & 13.183 & 2001 \\
\hline 13 & L. GLÓRIA & 13 & 13 & 55 & 8.660 & 1994 \\
\hline 14 & L. GRUTA / VORÁ / FURÃO & 64 & 64 & 253 & 29.978 & 2002 \\
\hline 15 & L. GUARA & 48 & 54 & 182 & 17.642 & 1999 \\
\hline 16 & L. GUARANI & 63 & 63 & 206 & 15.060 & 1996 \\
\hline 17 & L. GUAVIRA / SANTA CLARA & 102 & 105 & 391 & 16.555 & 2001 \\
\hline 18 & L. HAVAÍ & 30 & 28 & 115 & 11.724 & 1996 \\
\hline 19 & L. HEIDRICH & 36 & 40 & 152 & 7.578 & 1992 \\
\hline 20 & L. HERMANN & 28 & 31 & 96 & 11.364 & 2007 \\
\hline 21 & L. HORIZONTINA & 23 & 23 & 75 & 6.915 & 2003 \\
\hline 22 & L. LUDWIG & 48 & 46 & 102 & 17.395 & 1992 \\
\hline 23 & L. MARRECOS I & 18 & 19 & 66 & 11.540 & 1994 \\
\hline 24 & L. MARRECOS II & 13 & 13 & 51 & 5.996 & 1998 \\
\hline 25 & L. MARACANÃ & 50 & 50 & 198 & 18.735 & 2004 \\
\hline 26 & L. NEUHAUS & 25 & 25 & 84 & 10.272 & 2002 \\
\hline 27 & $\begin{array}{l}\text { L. OURO VERDE / FLOR DE } \\
\text { MAIO }\end{array}$ & 59 & 61 & 270 & 18.966 & 2001 \\
\hline 28 & L. PALMITAL & 24 & 24 & 93 & 11.114 & 2004 \\
\hline 29 & L. PASSO FUNDO & 41 & 40 & 173 & 17.602 & 1995 \\
\hline 30 & L. PAULISTA / SÃO LUIS & 22 & 22 & 75 & 10.324 & 2004 \\
\hline 31 & L. PERDIGÃO & 27 & 21 & 85 & 7.350 & 1997 \\
\hline 32 & L. PERU / SANGA DO MICO & 31 & 31 & 116 & 10.788 & 2004 \\
\hline 33 & L. PIACUÊ / FLOR DO OESTE & 65 & 67 & 201 & 20.328 & 2005 \\
\hline 34 & L. PORVENIL/CUNHAPORÃ & 42 & 44 & 157 & 13.756 & 1992 \\
\hline 35 & L. SANTO ANGELO & 29 & 29 & 118 & 8.770 & 1996 \\
\hline 36 & L. SANTOS DUMONT & 34 & 34 & 134 & 10.630 & \\
\hline 37 & $\begin{array}{l}\text { L. SÃO BERNARDO / BOM } \\
\text { FIM }\end{array}$ & 35 & 36 & 123 & 16.598 & 2007 \\
\hline 38 & L. SÃO CRISTOVÃO & 53 & 58 & 231 & 19.331 & 2007 \\
\hline 39 & L. SÃO CARLOS & 45 & 45 & 180 & 15.149 & 2004 \\
\hline 40 & L. SÃO JOSÉ DO GUAÇÚ & 38 & 38 & 152 & 15.769 & 2004 \\
\hline 41 & L. TRÊS VOLTAS / BAITACA & 50 & 53 & 195 & 24.628 & 2002 \\
\hline \multirow[t]{2}{*}{42} & L. WILHEMS / SÃO JOÃO & 106 & 109 & 360 & 54.549 & 2006 \\
\hline & TOTAL SISTEMAS & 1.871 & 1.923 & 6.806 & 713.387 & \\
\hline
\end{tabular}

Fonte: Léia Inês K. Bohnen, SAAE - Marechal Cândido Rondon, PR. 
Em março de 2011 o SAAE passou a realizar eventos para debater a importância dos sistemas de abastecimento rural e discutir com os dirigentes das associações a importância da preservação e do cuidado com o uso e manejo da água de forma sustentável. O $1^{\circ}$ Encontro dos Dirigentes das Associações de Usuários "Águas Rurais" oportunizou palestras de representantes da Funasa, do Instituto das Águas do Paraná, da Itaipu Binacional. A programação a seguir mostra o alcance e a importância dos temas discutidos com os usuários e dirigentes das aguas rurais: "Deveres e obrigações dos usuários de água a luz da nova lei do saneamento básico", ministrada pelo Dr. Marlon do Nascimento Barbosa (Cismae) e Dr. Edinei Carlos Dal Magro (Saae); "Controle de qualidade nos sistemas rurais de água”, pelo químico Laércio Miguel Richter (Biotecnal); “Técnica química”, por Roseléia Martini (Saae) e Glades Grudtner (20 ${ }^{\mathrm{a}}$ Regional de Saúde); "Águas Rurais”, por Odacir Fiorentin (Itaipu Binacional); "A importância da outorga”, por Márcio Fernando Nunes e Mario Kondo (Instituto das Águas do Paraná); e "O uso da água”, pelo engenheiro Raul Henrique Ribas Macedo (Funasa). (O Presente, 2011).

Figura 1: Primeiro Encontro dos Dirigentes das Associações de Usuários “Águas Rurais” de Marechal Cândido Rondon - PR

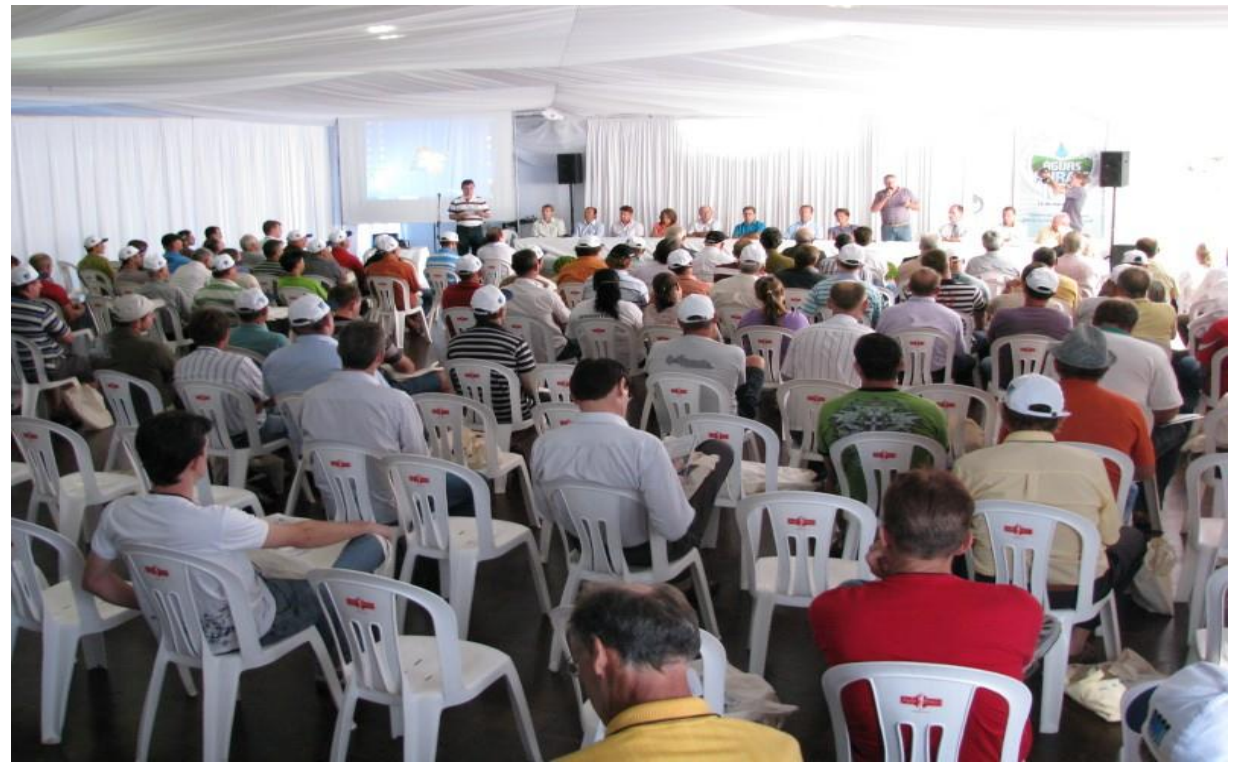

Foto: Leander Vorpagel/AquiAgora.net. 
Em 19 de março de 2012 o SAAE realizou o $2^{\circ}$ Encontro dos Dirigentes das Associações de Usuários “Águas Rurais”. “O evento, promovido pelo Serviço Autônomo de Água e Esgoto (Saae), chamou a atenção para a tendência de se adotar uma atitude sustentável no campo, de modo a garantir os elementos básicos para a viabilidade das atividades rurais.” (O PRESENTE, 2012).

Tais eventos contribuem para a construção de um debate permanente sobre a importância do acesso de água para todos e sobre a importância do cuidado, da preservação, e de uma distribuição democrática deste bem mais precioso para o mundo da vida destas comunidades rurais.

Diante disso, podemos afirmar que a Ética do Discurso, que se origina na ação comunicativa, constitui-se em importante instrumento para qualificar os sujeitos que protagonizam as ações nas Associações de Águas Rurais, para uma ação ética e competente na sociedade. A Ética do Discurso possibilita resgatar o conceito comunicativo de razão, orientada por uma ética que objetiva construir uma comunidade participativa e solidária na busca por um acesso igualitário à água e a sua proteção e cuidados para o bem de todos e para as gerações futuras.

\section{Conclusão}

O aporte da ação comunicativa proporciona uma ética discursiva que não mais exclui as contradições, transformando-se em práxis. Dessa forma se cria comunidades comunicativas nas quais se pensa de forma coletiva a questão do manejo e do uso sustentável da água. Assim todos os concernidos podem participar da discussão pública de todas as questões que envolvem a água e o saneamento básico.

Cabe aos governos municipais, expressão do poder local, juntamente com os sistemas de gestão das águas, a tarefa de construir processos participativos para que as políticas públicas visem à construção de consensos fundamentados em argumentos sociais, científicos, tecnológicos e espirituais. Desenvolver 
comunidades argumentativas em torno da questão da água significa debater a água como um problema ético, discutir e disseminar informações sobre o uso sustentável da água na agricultura e segurança alimentar, na indústria, sobre o uso das águas subterrâneas, sobre a proteção da água e sobre sua importância para a saúde e o saneamento básico. Urge construirmos uma sinergia em torno desse bem mais precioso para a humanidade.

\section{REFERÊNCIAS}

AHLERT, Alvori. A eticidade da educação: o discurso de uma práxis solidária/universal. 2 ed. Ijuí, RS: UNIJUÍ, 2003.

BOFF, Leonardo. Ethos mundial: um consenso mínimo entre os humanos. Brasília: Letraviva, 2000.

FERRARI, Walter Junior. A expansão territorial urbana de Marechal Cândido Rondon - PR: a produção da cidade a partir do campo. 2009. 178 f. Dissertação (Mestrado) Universidade Federal da Grande Dourados, Programa de Pós-graduação em Geografia, Grandes Dourados. Disponível em: <http://www.ufgd.edu.br/fch/mestradogeografia/dissertacoes/a-expansao-territorial-urbana-de-marechal-candido-rondon-pr-aproducao-da-cidade-a-partir-do-campo>. Acesso em: 18 de maio 2013.

FREITAG, Bárbara. Habermas e a filosofia da modernidade. Perspectiva, São Paulo, v.16, p. 23-45, 1993

GEERTZ, Clifford. A interpretação das culturas. 13. reimpr. Rio de Janeiro: LTC, 2008.

GIL, Antônio Carlos. Métodos e técnicas de pesquisa social. 5 ed. São Paulo: Atlas, 1999.

HABERMAS, J. Consciência moral e agir comunicativo. Rio de Janeiro: Tempo Brasileiro, 1989.

INSTITUTO BRASILEIRO DE GEOGRAFIA E ESTATÍSTICA - IBGE. Cidades@. Paraná, Marechal Rondon, infográficos: dados gerais do município. Disponível em:

<http://cidades.ibge.gov.br/painel/painel.php?codmun=41146o > . Acesso em: 18 maio 2013 .

MARCONDES, Dal. Fluidez para os negócios. Carta Capital, São Paulo, 27 de março de 2013, p. 36-39. 
MAWHINNEY, Mark. Desenvolvimento sustentável: uma introdução ao debate ecológico. São Paulo: Loyola, 2005.

MEINCKE, Silvio. A fonte. São Leopoldo: Sinodal, 1983.

OLIVEIRA NETTO, Alvim Antônio de. Metodologia da pesquisa científica: Guia prático para a apresentação de trabalhos acadêmicos. 2. Ed. ver. e atual. Florianópolis: Visual Books, 2006.

O PRESENTE. Saae promove evento no próximo dia 15. 03/03/2011. Disponível em: <http://www.opresente.com.br/geral/saae-promove-evento-no-proximo-dia-15-10430/>. Acesso em: 18 abr. 2013.

O PRESENTE. Evento enfoca a preservação de águas rurais. 20 mar. 2012. Disponível em: <http://www.opresente.com.br/geral/evento-enfoca-preservacao-deaguas-rurais-21925/>. Acesso em: 18 abr. 2013.

PIVÔS de irrigação são alternativa para produtores de soja enfrentarem estiagem. Disponível em: <http://sojabrasil.ruralbr.com.br/noticia/2013/o1/pivos-de-irrigacao-saoalternativa-para-produtores-de-soja-enfrentarem-estiagem-4025729.html>. Acesso em: o6 fev. 2013.

PIZZI, Jovino. Ética do discurso: a racionalidade ético-comunicativa. Porto Alegre: EDIPUCRS, 1994.

PREFEITURA MUNICIPAL DE MARECHAL CÂNDIDO RONDON. Relatório de Leitura da Realidade Municipal. Vertrag Planejamento, 2007. Disponível em: <http: //www.mcr.pr.gov.br/down.php?setFile=01994f2c9a.pdf $>$. Acesso em: 18 maio 2013.

REDONDO, Manuel Jiménez. Introducción. In: HABERMAS, Jürgen. Escritos sobre moralidad y eticidad. Barcelona: Paidós, 1991. p. 9-62.

REIS, Cleiber et al. Consumo de água e energia em sistemas de irrigação por pivô central equipados com emissores tipo lepa utilizados na cafeicultura. VII Simpósio Brasileiro de Pesquisa em Cafeicultura Irrigada. Disponível em: <http://www.sbicafe.ufv.br/bitstream/handle/10820/1655/166733_Arto85f.pdf?sequenc $\mathrm{e}=1>$. Acesso em: 06 fev. 2013.

SELBORNE, Lord. A Ética do Uso da Água Doce: um levantamento. Brasília: UNESCO, 2001.

SOUZA, Herbert de. Ética e cidadania. São Paulo: Moderna, 1994.

WEIRICH, Udilma Lins. História e atualidade: Perfil de Marechal Cândido Rondon. Marechal Cândido Rondon: Germânica, 2004. 